\title{
AUC Dosing to Last Concentration Normalized by Dose
}

National Cancer Institute

\section{Source}

National Cancer Institute. AUC Dosing to Last Concentration Normalized by Dose. NCI

Thesaurus. Code C92310.

The area under the curve (AUC) from the time of dosing to the last measurable concentration divided by the dose. 